\title{
Optimal Operating Scenario for Polerood Hydropower Station to Maximize Peak Shaving and Produced Profit
}

\author{
Behzad Forouzi Feshalami ${ }^{1}$
}

Department of Mechanical Engineering, Ferdowsi University of Mashhad, Mashhad, Khorasan Razavi, Iran

\begin{abstract}
This paper deals with the optimization of the daily operation of Polerood hydropower station being constructed in the north of Iran. Dynamic Programming method (DP) is applied as the preferred optimization tool owing to the fact that it guarantees the optimal solution and is applicable to the present problem. Produced profit and peak-shaving are the two objectives considered separately in this study. The results show that the optimal water management of the case study through charging and discharging the reservoir at the appropriate times led to $4 \%$ increase in the produced profit. In another part of this study, the optimal performance strategies regarding to the two objectives (produced profit and peak-shaving) are compared. The observed similarity between the two performance strategies implies the substantial dependence of the electricity price and the network demand level. The paper ends with the profitability study of the project and the sensitivity analysis of the results to various economic parameters.
\end{abstract}

Keywords: Polerood Hydropower Station; Performance Optimization; Dynamic Programming Method; Profit; Peak Shaving

Article History: Received December 15 th 2017 ; Received in revised form April 18 ${ }^{\text {th }} 2018$; Accepted September 16 ${ }^{\text {th }} 2018$; Available online How to Cite This Article: Feshalami, B.F. (2018) Optimal Operating Scenario for Polerood Hydropower Station to Maximize Peak Shaving and Produced Profit. International Journal of Renewable Energy Development, 7(3), 233-239. https://doi.org/10.14710/ijred.7.3.233-239

\section{Introduction}

Global energy demand has grown from 6630 million tons of oil (MTO) in 1980 to 11295 MTO in 2008 with the rate of $5.4 \%$ per year (Darmstader, Teitelbaum, \&Polach 1971, Martinot 2005, Finley 2013) . The crude oil and natural gas resources will be depleted in the coming decades (Barten 2010). Furthermore, the greenhouse gases being generated from the fossil fuels have serious effects on human's lives (Hosseini \& Wahid 2013).

Using the renewable sources of energy is the most valuable approach to overcome the previously mentioned problems(Nautiyal, Singal, \&Sharma 2011). Among the renewable forms of energy, hydroelectric energy with the approximate production cost of $0.04 \$ / \mathrm{kWh}$ seems to be more economical(Delucchi \& Jacobson 2011). Moreover, the hydroelectric systems are easy from the maintenance standpoint based on their simple design, and the energy generated by these systems is more reliable in comparison to the other renewable systems (Egré \& Milewski 2002, Gaudard \& Romerio 2014).

Traditional patterns of water management cannot cope with today's needs including various objectives and constraints; accordingly, the optimal management of hydropower systems seems to be necessary (Labadie 2004, Lu et al. 2013).

Various research works have been performed concerning the performance optimization of the hydropower systems. Mariano et al. (2008) included the water head variations into the modelling of a Hydro Power Station (HPS) and employed "Non-linear Programming method" to maximize the power production. The results showed an improvement compared to those obtained by "Linear Programming method (LP)" which ignored the head variations. A similar work was carried out by Mariano et al. (2007) and Pérez-Díaz, Wilhelmi, \& Sánchez-Fernández (2010); however, in Mariano et al. (2007) study, the produced profit was considered as the objective function instead.

In recent years, combination of hydropower plant with the other ones, namely wind energy and solar energy, has extensively been investigated by researchers. The feasibility of the hydro-photovoltaic operation has been investigated by Fang et al. (2017). They aimed to find the optimal size of photovoltaic plant to maximize the net revenue during life time. By using linear programming, Feng et al. (2017) optimized the combination of the hydro-thermal-nuclear plants operation in order to shave peak load of the East China Power Grid.

Short term hydro-thermal scheduling problem with the aim of minimizing the operating costs was considered in the research of Simopoulos, Kavatza, \& Vournas (2007). In this study, "Simulated Annealing Algorithm" and a new method named "Enhanced Peak Shaving method" were used as the optimization tools for the thermal and hydro sub-problems,

\footnotetext{
${ }^{1}$ Corresponding author: behzadforouzifeshalami@mail.um.ac.ir
} 
respectively. A new method named "Self-Learning Genetic Algorithm (GA)" was proposed by Hakimi-Asiabar, Ghodsypour, \& Kerachian (2010) to optimize the operation of "Dez" HPS in Iran. The results showed improvements in the objective value and convergence speed in comparison to the previous version called "Som-Based Multi-objective Genetic Algorithm”. Pérez-Díaz \& Wilhelmi (2010) applied "Mixed Integer Linear Programming (MILP)" to maximize the produced profit of a real HPS. Some environmental constraints such as a limitation for the rate of change of discharged flow were considered in this study. Multi-objective performance optimization of a hydropower station, with the aim of maximizing power generation and minimizing the difference between the power production and demand, was addressed by Afshar (2012). In this study, "Partially Constrained Particle Swarm Optimization (PSO)" and "Fully Constrained PSO" methods were employed, and the better results with lower computation times were achieved in comparison to the simple PSO and GA. Chen et al. (2013) employed GA to maximize the power generation of a HPS with some environmental constraints. The results showed that $50-70 \%$ of the fishes survived at the expense of $3.6-6 \%$ reduction in the generated energy.

Multi-objective optimization of eight cascaded reservoirs by using a hybrid global optimization algorithm was addressed by Jiekang, Zhuangzhi, \& Fan (2014). Maximization of the generated power and maximization of the volume of water stored behind the reservoirs constituted the objectives of this study. Xu \& Tao (2012) used "Brindom Simulation based GA" for multi-objective optimization of a HPS. Appropriate water allocation to different consumers (e.g., irrigation, and residential and industrial users), as well as the maximum balance between the power production and demand constituted the objectives of this work. The selected method was evaluated through comparing the results to those obtained from "Fuzzy Programming" and "Stochastic" methods.

Optimization tools have been used by JahandidehTehrani, Bozorg Haddad, \& Loáiciga (2015) to overcome climate changes. They showed that higher energy production can be obtained by applying optimization tools. Based on different inflow rates and electricity prices, Mahmoudimehr, Sorouri, \& Feshalami (2016) presented a novel map in order to choose the best type of a hydropower plant from economical factors points of view. the uncertainty in future prices and inflow on stochastic shortterm hydropower scheduling has also been investigated by Belsnes et al. (2016). Gaudard, Avanzi, \& De Michele (2017) weighed the effects of price seasonality variation on revenue against climate change and concluded that price seasonality causes more uncertainty on revenue than climate change.

There also exist some other research works (Chatterjee, Howitt, \&Sexton 1998, Mantawy, Soliman, \&El-Hawary 2003, Chen, McPhee, \&Yeh 2007, Sharma, Jha, \&Naresh 2007, Borghetti et al. 2008, Yoo 2009, Amjady \& Soleymanpour 2010, Fu et al. 2011, Ma, Lian, \&Wang 2013, Zhang et al. 2013, Yang et al. 2015, BozorgHaddad et al. 2017) which have employed different optimization methods, including Tabu Search, Neural Network, GA, MILP, LP, DE, PSO, symbiotic organisms search, and MOSPD to optimize the operation of a hydropower station. The produced profit, generated power, production duration, operating costs, and the difference between power production and demand, constitute the various objectives which considered in these works.

Optimization approaches can be classified into a number of primary groups, including the mathematical (derivative-based and derivative free), heuristic (unproven and originated from the past experiences), and evolutionary (such as GA) algorithms(Koziel \& Yang 2011). On condition that DP, as a derivative-free mathematical method, is applicable to a problem, it guarantees the global optimal solution, whereas the other previously mentioned methods do not and may be trapped in a local optimum solution(Pérez-Díaz \& Wilhelmi 2010, Afshar 2012, Chen et al. 2013). A local optimum is a selection which is only better than the neighbouring selections. By contrast, a global optimum is a selection from a given domain which is better than any other selection in that domain.

The main objective of this paper is to Apply DP to optimize the daily operation of Polerood HPS being constructed in the north of Iran. Furthermore, the optimization procedure is executed for two different objectives (i.e., the produced profit and peak shaving). The optimal operating strategies related to the two considered objectives are Compared and analysed. Additionally, the profitability of the project is Investigated and its sensitivity to various parameter is reported.

\section{Problem definition}

Fig. 1 shows a schematic view of the hydropower system considered in this study.

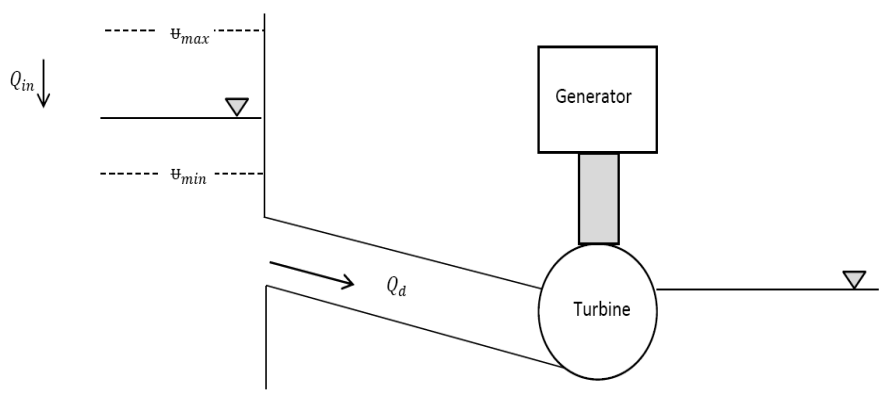

Fig.1. schematic view of a hydroelectric plant

Eqs. (1)-(7) show the objective functions and constraints of the problem which are explained in the following.

$$
\begin{gathered}
\text { Maximize }\left[\sum_{i=1}^{T} P_{G, i} . \text { Price }_{i}\right] \\
\text { Minimize }\left[\sum_{i=1}^{T}\left(P_{G, i}-P_{\text {sh }, i}\right)^{2}\right] \\
; \begin{cases}\text { if } P_{\text {demand }, i}>P_{\text {capacity }} & \rightarrow P_{\text {sh }, i}=P_{\text {demand }, i}-P_{\text {capacity }} \\
\text { else } & \rightarrow P_{s h, i}=0\end{cases}
\end{gathered}
$$


$P_{G, i}=\alpha \cdot Q_{d, i} \cdot \eta$

$v_{i}=v_{i-1}+\left(Q_{i n, i}-Q_{d, i}\right) \cdot \Delta t$

$v_{\min }<v_{i}<v_{\max }$

$0 \leq Q_{d, i} \leq Q_{d, \max }$

$v_{T} \geq v_{0}$

Eq. (1) defines the total produced profit as the first objective function. In Eq. (1), $P_{G, i}$ and Price $_{i}$ represent the generated power $(W)$ and electricity price $(\$ / \mathrm{kWh})$, respectively, at time interval i. In this study, the operation is to be optimized over a period of one day, and the whole period was divided into 24 one-hour intervals. Also, $T$ represents the time period (h).

Eq. (2) defines the peak shaving as the second objective function. In Eq. (2), $\mathrm{P}_{\text {sh }}$ denotes the power shortage $(W)$ which is defined as the difference between the network capacity (i.e., the maximum power that can be supplied to the network) and power demand when the latter exceeds. $P_{\text {demand }}$ and $P_{\text {capacity }}$ are Network capacity $(W)$ and Electrical power demand $(W)$, respectively.

Eq. (3) shows the generated power as a function of discharged flow rate through the turbines $\left(Q d\left(\mathrm{~m}^{3} / \mathrm{s}\right)\right)$. In this equation $\eta$ denotes mechanical to electrical energy conversion efficiency, and $\alpha$ is a head dependent parameter which is considered as a constant coefficient in this study.

Eq. (4) shows the reservoir's mass balance. In this equation $Q_{i n}$ and $v$ designate the reservoir's inflow rate $\left(\mathrm{m}^{3} / \mathrm{s}\right)$ and the volume $\left(\mathrm{m}^{3}\right)$ of water behind the reservoir, respectively. $v_{\min }$ and $v_{\max }$ are the minimum and maximum volumes of the water behind the dam, respectively. Eq. (5) specifies a permissible range for the volume of water behind the reservoir. Eq. (6) shows the maximum allowable rate of flow passing through the turbines.

Based on the constraint shown in Eq. (7), the final volume of water behind the reservoir $\left(v_{\mathrm{T}}\right)$ must be greater than or equal to its initial value $\left(v_{0}\right)$.

\section{Dynamic Programming Algorithm and Verification of the Developed Program}

DP method was invented by an American mathematician named Bellman(Bellman 2013). This method has been described in some references (Carter , Marano, Rizzo, \&Tiano 2012, Mahmoudimehr, Sorouri, \&Feshalami 2016). This section explains how DP is applied to the problem under study. For each time interval, the volume of water behind the reservoir is considered to be the decision variable. Consequently, $\left[v_{1}, v_{2}, \ldots, v_{T}\right]$ is the set of decision variables of the problem. At first, the continuous range of each decision variable (i.e., the domain with the lower and upper bounds of $v^{\text {min }}$ and $v^{\text {max }}$ ) must be discretized into a set of discrete values $\left\{v^{\min }, v^{\min }+\Delta v, v^{\min }+2 \Delta v, \ldots, v^{\max }\right\}$, where $\Delta v$ denotes the step size of discretization. Accordingly, the optimal value of each decision variable is to be selected from the set of discrete values instead of the continuous range. If $\Delta v$ is sufficiently small, the solution will be sufficiently close to the global optimum.

The DP procedure is the same for the two objectives; therefore, the DP method is only explained for the first objective (i.e., maximization of produced profit). The DP procedure is mathematically shown in Eq. (8). It is worth noting that the initial water head $\left(v_{0}\right)$ is considered to be a known value. The revenue in a time interval, Objective , can be considered as a function of only the heads of water at the beginning and at the end of that time interval (i.e., $v_{i-1}$ and $v_{i}$, respectively).

As shown in Eq. (8), in the first step of the DP procedure, only the first two time intervals are considered. The total revenue from the beginning to the end of time interval 2 is the sum of the revenues in time interval 1 (Objective $\left.1\left(v_{o}, v_{1}\right)\right)$ and time interval $2\left(\operatorname{Objective}_{1}\left(v_{o}, v_{1}\right)\right)$. In this step, as shown in Eq. (8), for each discrete value of $v_{2}$, the maximum possible revenue from the beginning to the end of time interval 2 (denoted by Objective $0-2\left(v_{2}\right)$ ) is found through examining all discrete values of $v_{1}$. After this step, $v_{1}$ is no longer an independent decision variable because for each value of $v_{2}$ the best value of $v_{1}$ has been determined. Therefore, $v_{1}$ can be removed from the decision vector. Assuming that the continuous range of each decision variable is discretized into $N$ discrete values, the order of computational complexity of the first step is $N^{2}$.

$$
\begin{aligned}
& \text { First step : } \text { Objective }_{0-2}\left(v_{2}\right)=\max _{h_{l}}\left\{\text { Objective }_{I}\left(v_{0}, v_{I}\right)+\text { Objective }_{2}\left(v_{l}, v_{2}\right)\right\} \\
& \text { second step : Objective } e_{0-3}\left(v_{3}\right)=\max _{h_{2}}\left\{\text { Objective }_{0-2}\left(v_{2}\right)+\text { Objective }_{3}\left(v_{2}, v_{3}\right)\right\}
\end{aligned}
$$

$$
\text { Last step : } \text { Objective }_{0-24}\left(v_{24}\right)=\max _{h_{23}}\left\{\text { Objective }_{0-23}\left(v_{23}\right)+\text { Objective }_{24}\left(v_{23}, v_{24}\right)\right\}
$$

In the second step, one more time interval is considered. In this step, as shown in Eq. (8), for each discrete value of $v_{3}$, the maximum possible revenue from the beginning to the end of time interval 3 (denoted by Objectiveo-s $\left(v_{3}\right)$ is determined through examining all discrete values of $\left(v_{2}\right)$. It is worth mentioning that Objective $0_{-2}\left(v_{2}\right)$ has been computed in the previous step and does not need to be computed again. Moreover, $v_{2}$ is no longer an independent decision variable and can be removed from the decision vector. Similar to the first step, the order of computational complexity of this step is $N^{2}$.

The procedure continues until the maximum revenue from the beginning to the end of time interval 24 (denoted by Objective $0-24$ ) is obtained as a function of only $v_{24}$; hence, the maximum daily revenue can be obtained through examining all values of $v_{24}$

Since for each value of $v_{i}$, the optimal value of $v_{i-1}$ has been determined during the DP steps, after the optimal value of $v_{24}$ is found, the optimal values of $v_{23}$ to $v_{1}$ can be obtained one by one through a back-tracking process. Based on the previously described procedure, the DP method reduces the order of computational complexity from $N^{24}$ (because there are 24 decision variables and each decision variable can take $N$ discrete values) to $24 N^{2}$. 
DP method guarantees the optimal solution based on its mathematical logic which has been described. However, to verify the optimization computer code developed by these authors, it is applied to a problem defined in Zhao \& Davidson (2009) study and the results are compared to those of (Zhao \& Davison 2009) which were also obtained by DP method.

The specifications of the verification case study are as follows: The operating period of 48 hours, the natural inflow rate of $3 \pi\left(\mathrm{m}^{3} / \mathrm{s}\right)$, the initial head of $120 \mathrm{~m}$, the minimum and maximum allowable heads of $120 \mathrm{~m}$ and 180 $\mathrm{m}$, respectively, a cubic reservoir with the surface area of $3600 \pi\left(\mathrm{m}^{2}\right)$, and the constant electricity price of $1 \$ / \mathrm{MWh}$.

Fig. 2 shows a comparison of the optimal time variation of the water head behind the reservoir obtained in the present work to that reported by Zhao \& Davidson (2009). As is observed, the results are acceptably matched with the negligible maximum difference of about $0.2 \%$.

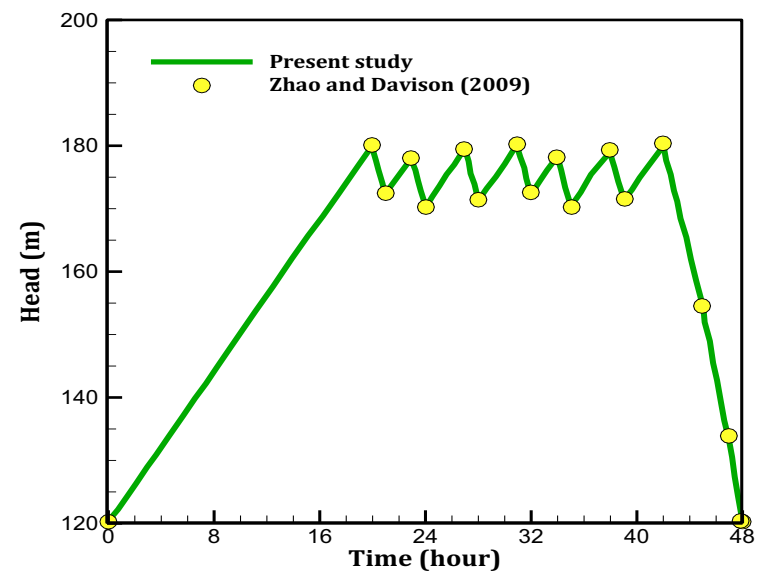

Fig.2. Comparison of the optimal time variation of water head in the nresent work and that of 7han \& Davison (2009)

\section{Case study: Polerood hydro power station}

"Polerood" HPS is under construction on" Polerood" river in Guilan province located in the north of Iran. The installed capacity will be 16.6 MW (composed of two 8.3MW units). For this case, $Q_{d}^{\max }, Q_{i n}, \alpha$ and $\eta$, were considered to be $20,8,10^{6}$, and 0.83 , respectively.

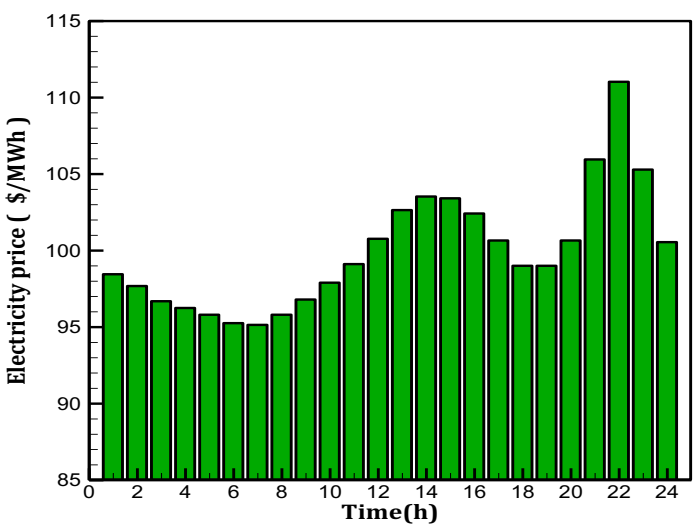

Fig.3. Electricity price scenario

Fig. 3 illustrates the electricity price scenario needed for the first objective function (the produced profit). Fig. 4 shows the network capacity as well as the hourly data of Iran's electrical power demand. The red filled bars in this figure indicate the times at which the demands are greater than the network capacity (or there exist power shortages). It is worth mentioning that the value of inflow rate and the data in Figs. 3 and 4 are related to a representative summer day.

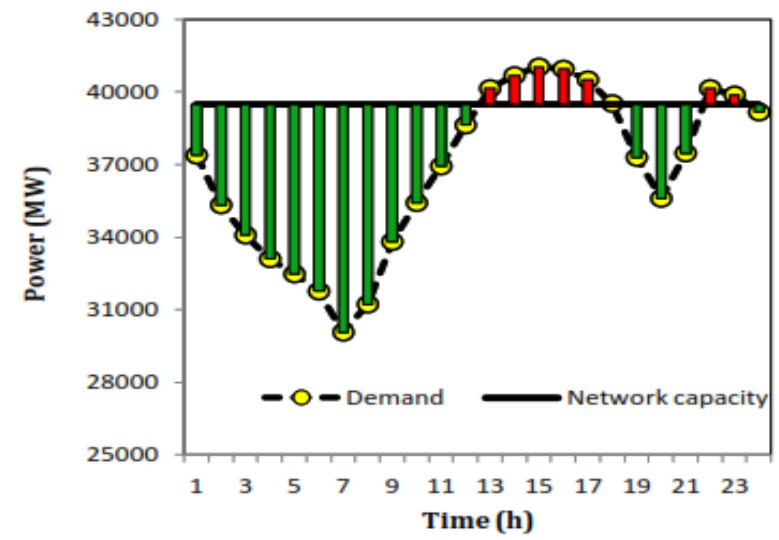

Fig. 4. Iran's electrical power demand

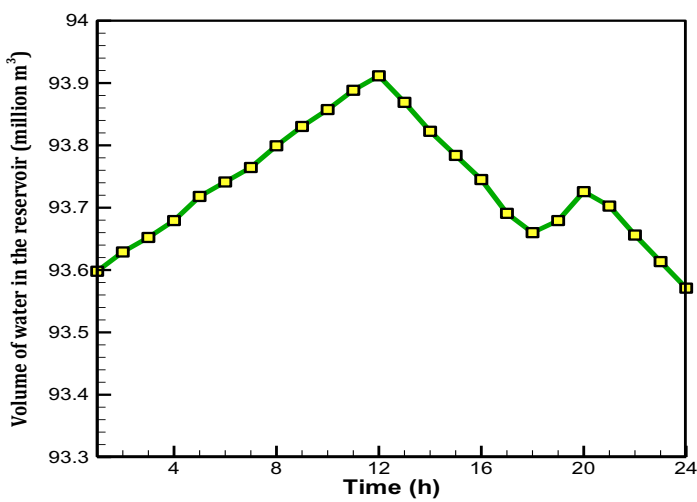

Fig. 5. Optimal time variation of the volume of water hehind the recervoir

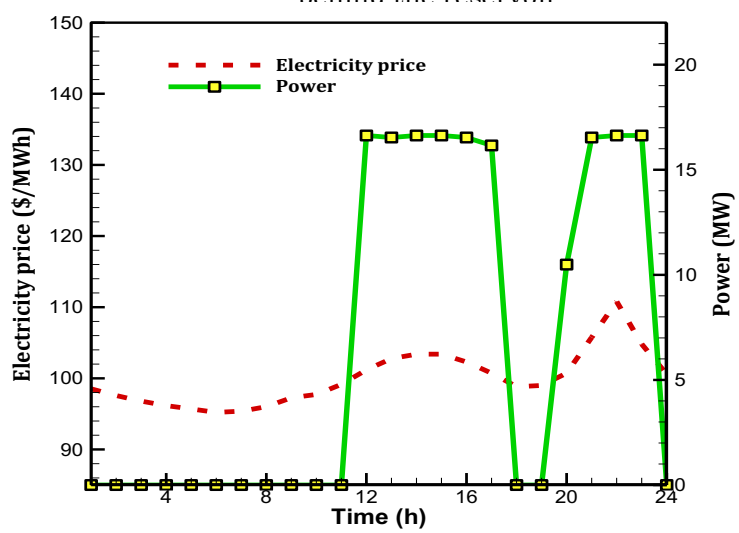

Fig 6. Hourly power generation corresponding to the maximum profit

\section{Results and discussion}

The results of the first and second objective functions as well as their comparison, and the profitability study of the project are presented in this section. 


\subsection{Profit maximization}

Fig .5 illustrates the optimal set of decision variables $\left(\left[\mathrm{n}_{0}, \mathrm{n}_{1}, \ldots, \mathrm{n}_{24}\right]\right)$. Furthermore, the optimal hourly variation of the generated power, related to the optimal solution, along with the electricity price scenario, is shown in Fig .6. Fig.6 illustrates how the generated power follows the electricity price scenario to achieve the maximum total profit.

As shown in Fig. 5, the water is stored behind the reservoir at the times with low electricity prices, and the stored water is discharged to produce maximum electricity during periods of high electricity prices. To estimate the benefit of using the optimization procedure for determining the performance strategy, the optimal objective value (i.e., $16532 \$$ ) is compared to that obtained by assuming that the volume of water behind the reservoir does not change with time. This assumption, which implies that the discharged flow through the turbines equals the inflow $Q_{i n, i}=Q_{d, i}$ at all times, yielded the objective value of $15936 \$$ which was about $4 \%$ lower than that obtained through optimization process.

\subsection{Peak shaving}

Fig 7 shows optimal time variation of generated power along with the time variation of the power shortage. This figure indicates how the generated electrical power follows the power shortage. As shown, the electricity generation is zero for initial times of operation because as mentioned before, the contents of network capacity are higher than that of demand. However, by reaching to the peak time of consumption, this point is reversed. Therefore, the power plant begins to produce power in order to compensate the lack of demand power. Additionally, this figure shows trueness of the algorithm applied in this research. Consequently, it can be claimed that this scenario is the optimal condition to shave peak load presented in this research.

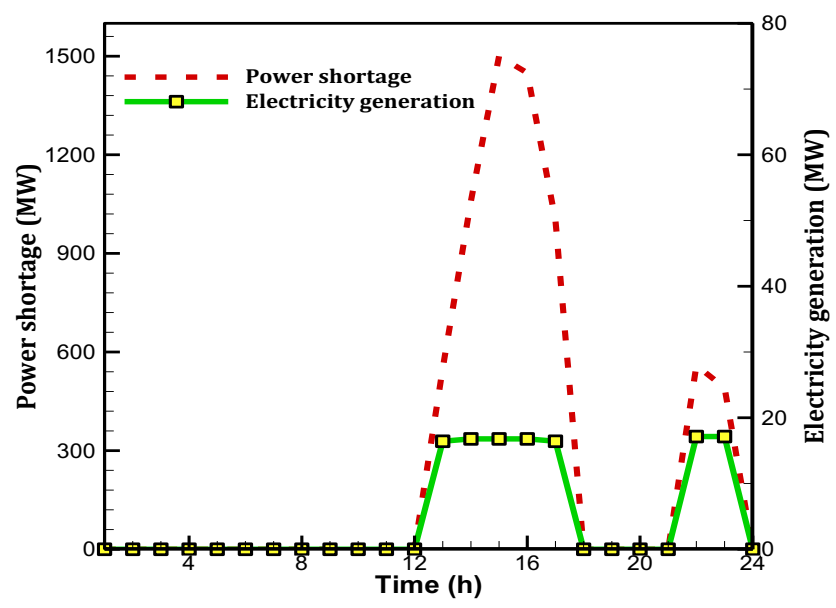

Fig.7. Hourly power generation corresponding to the maximum

\subsection{Comparing the results of the two objective functions}

Fig. 8 compares the optimal performance curves obtained for the two different objective functions (i.e., profit and peak shaving). The similarity between the performance strategies implies that the electricity price is significantly related to the demand level. This could also be perceived through comparing Figs. 3 and 4 where the price has the same trend as the power demand. However, the observed discrepancies in Fig. 8, shows a need for modifying the price scenario.

Table 1

Specification of the project

\begin{tabular}{|ccccc|}
\hline $\boldsymbol{C}_{\boldsymbol{I}}(\mathrm{M} \$)$ & $n$ (year) & $m$ & $I$ & $\begin{array}{c}\text { Annually } \\
\text { averaged inflow } \\
\text { rate }\left(\mathrm{m}^{3} / \mathrm{s}\right)\end{array}$ \\
\hline 70 & 70 & 0.02 & 0.05 & 15 \\
\hline
\end{tabular}

\subsection{Profitability Study and Sensitivity Analysis}

This section is concerned with investigating the economic feasibility of the project and the sensitivity of the results to the various parameters.

In this work, Net Present Value (NPV) is considered as the criterion for the feasibility study. NPV, which is expressed in Eq. (9), is defined as the net value of all benefits and costs of the project, discounted back to the beginning of the investment. If the NPV is greater than zero, the project is considered to be economically acceptable as it will bring profit to the investor. In Eq. (9), $B_{A}$ denotes annual revenue from electricity sales, $I$ shows interest rate, n represents the lifetime of the system, and $\mathrm{C}_{\mathrm{I}}$ is the initial investment cost.

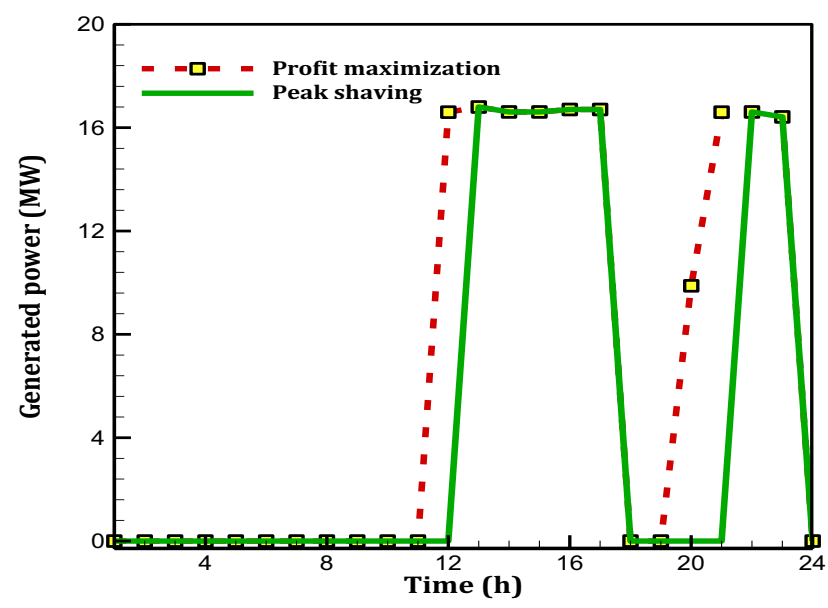

Fig. 8. Comparison of the optimal power generation scenarios in the first and second objectives

Moreover, the annual operating and maintenance cost is considered to be a fraction $(m)$ of the initial investment cost.

$N P V=B_{4}\left[\frac{(1+I)^{n}-1}{I(1+I)^{n}}\right]-C_{t}\left[1+m\left(\frac{(1+I)^{n}-1}{I(1+I)^{n}}\right)\right]$

The economic specifications of the project together with the annually averaged inflow rate are gathered in Table 1 . The electricity price scenario has been previously shown in Fig. 3 , and $B_{A}$ (annual revenue) is obtained through optimization procedure which has been previously discussed. Calculations, based on the information presented in Table 1 , resulted in the approximate annual revenue and NPV of $11.1 \mathrm{M} \$$ and $117.6 \mathrm{M} \$$, respectively. The positive value of NPV indicates that the project is economically feasible. However, regarding to the fact that the parameters of Table 1 have the uncertain nature, the sensitivity of the results to these parameters is studied and illustrated in Fig. 9. 


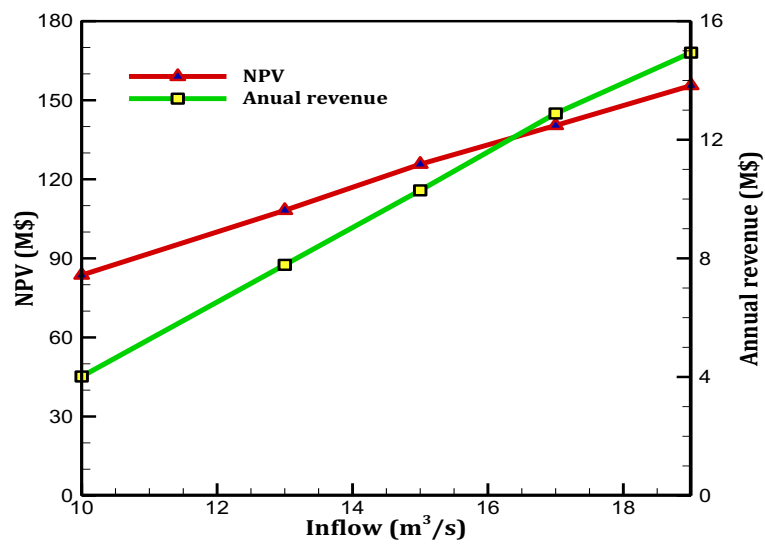

Fig.9a. NPV and annual revenue as functions of inflow rate

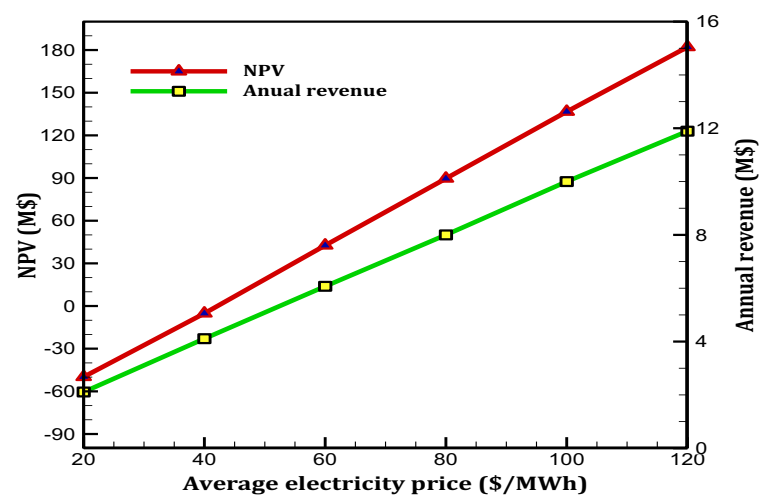

Fig.9b. NPV and annual revenue as functions of electricity price

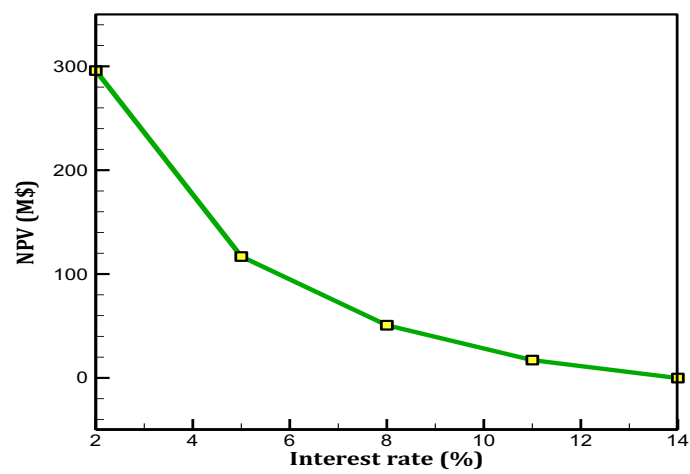

Fig.9c. NPV as a function of interest rate

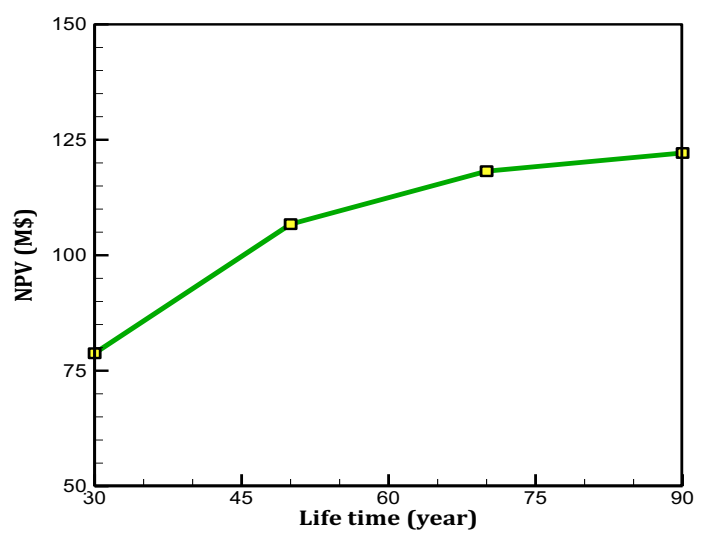

Fig.9d. NPV as a function of project lifetime

Fig.9. Sensitivity analysis of NPV and annual revenue
Fig. 9a illustrates the sensitivity of NPV and $B_{A}$ to the inflow rate. This figure indicates that both NPV and $\mathrm{B}_{\mathrm{A}}$ increase with inflow rate. Moreover, the project is economically feasible (i.e., takes positive value of NPV) for the considered range of inflow rate (10 to $\left.19 \mathrm{~m}^{3} / \mathrm{s}\right)$.

The electricity price scenario previously shown in Fig. 3 with the average value of $100 \$ / \mathrm{MWh}$ was considered as the base price scenario. To study the effect of electricity price on the feasibility of the project, calculations were carried out for the different average values of electricity price (from 20 $\$ / \mathrm{MWh}$ to $120 \$ / \mathrm{MWh}$ ), and the results are shown in Fig. 9b. As is observed, both NPV and $\mathrm{B}_{\mathrm{A}}$ increase with the electricity price. Moreover, the results show that the project becomes unprofitable for the average electricity price below $40 \$ / \mathrm{MWh}$. The effects of interest rate, and the lifetime of project, on NPV are shown in Figs. 9c and 9d, respectively. It is observed that NPV increases with lifetime, but decreases with interest rate. Fig. 9d indicate that the project is profitable (with positive values of NPV) for the considered lifetime (30-90 years). However, Fig. 9c shows that the project is acceptable up to an interest rate of 14 per cent.

\section{Conclusion}

Dynamic programming method guarantees the optimal solution and therefore is of great importance. The present study describes how to use dynamic programming method to optimize the daily operation of a hydropower station.

Then, the DP method was applied to "Polerood" dam which is being constructed in the north of Iran. The results were obtained for the two different objective functions (profit and peak-shaving). It was observed that the optimization process could improve the results. Comparison of the results of the two objectives confirms the fact that electricity price is mainly a function of demand level. However, the observed discrepancy shows that the price scenario should be updated as the network capacity and/or the power demands change. Finally, it was shown that the project is profitable based on the net present value (NPV) criterion, and the sensitivity of the economic feasibility of the project to various economic parameters was investigated.

\section{References}

Afshar, M. H. (2012). Large scale reservoir operation by Constrained Particle Swarm Optimization algorithms. Journal of Hydro-environment Research, 6(1), 75-87.

Amjady, N., \& Soleymanpour, H. R. (2010). Daily Hydrothermal Generation Scheduling by a new Modified Adaptive Particle Swarm Optimization technique. Electric Power Systems Research, 80(6), 723-732.

Barten, H. (2010). International Energy Agency.

Bellman, R. (2013). Dynamic programming, Courier Corporation.

Belsnes, M. M., Wolfgang, O., Follestad, T., \& Aasgård, E.K. (2016). Applying successive linear programming for stochastic short-term hydropower optimization. Electric Power Systems Research, 130, 167-180.

Borghetti, A., Ambrosio, C. D., Lodi, A., \& Martello, S.(2008). An MILP Approach for Short-Term Hydro Scheduling and Unit Commitment With Head-Dependent Reservoir. IEEE Transactions on Power Systems, 23(3), 1115-1124.

Bozorg-Haddad, O., Azarnivand, A., Hosseini-Moghari, S.-M., \& Loáiciga, H. A. (2017). Optimal operation of reservoir systems with the symbiotic organisms search (SOS) algorithm. Journal of Hydroinformatics, 19(4).

Carter, R. G. Pipeline Optimization: Dynamic Programming After 30 Years, Pipeline Simulation Interest Group. 
Chatterjee, B., Howitt, R. E., \& Sexton, R. J. (1998). The Optimal Joint Provision of Water for Irrigation and Hydropower. Journal of Environmental Economics and Management, 36(3), 295-313.

Chen, L., McPhee, J., \& Yeh, W. W. G. (2007). A diversified multiobjective GA for optimizing reservoir rule curves. Advances in Water Resources, 30(5), 1082-1093.

Chen, Q., Chen, D., Li, R., Ma, J., \& Blanckaert, K. (2013).Adapting the operation of two cascaded reservoirs for ecological flow requirement of a de-watered river channel due to diversion-type hydropower stations. Ecological Modelling, 252, 266-272.

Darmstader, P. D., Teitelbaum, P. D., \& Polach, J. G. (1971). Energy in the world economy: a statistical review of trends in output, trade, and consumption since 1925, The Johns Hopkins Press,Baltimore; None.

Delucchi, M. A., \& Jacobson, M. Z. (2011). Providing allglobal energy with wind, water, and solar power, Part II: Reliability, system and transmission costs, and policies. Energy Policy, 39(3), 1170-1190.

Egré, D., \& Milewski, J. C. (2002). The diversity of hydropower projects. Energy Policy, 30(14), 1225-1230.

Fang, W., Huang, Q., Huang, S., Yang, J., Meng, E., \& Li, Y. (2017). Optimal sizing of utility-scale photovoltaic power generation complementarily operating with hydropower: A case study of the world's largest hydro-photovoltaic plant. Energy Conversion and Management, 136, 161-172.

Feng, Z.-k., Niu, W.-j., Cheng, C.-t., \& Zhou, J.-z. (2017). Peak shaving operation of hydro-thermal-nuclear plants serving multiple power grids by linear programming. Energy, 135, 210-219.

Finley, M. (2013). BP statistical review of world energy.

Fu, X., Li, A., Wang, L., \& Ji, C. (2011). Short-term scheduling of cascade reservoirs using an immune algorithm-based particle swarm optimization. Computers \& Mathematics with Applications, 62(6), 2463-2471.

Gaudard, L., Avanzi, F., \& De Michele, C. (2017). Seasonal aspects of the energy-water nexus: The case of a run-ofthe-river hydropower plant. Applied Energy.

Gaudard, L., \& Romerio, F. (2014). The future of hydropower in Europe: Interconnecting climate, markets and policies. Environmental Science \& Policy, 43, 5-14.

Hakimi-Asiabar, M., Ghodsypour, S. H., \& Kerachian, R. (2010). Deriving operating policies for multi-objective reservoir systems: Application of Self-Learning Genetic Algorithm. Applied Soft Computing, 10(4), 1151-1163.

Hosseini, S. E., \& Wahid, M. A. (2013). Feasibility study of biogas production and utilization as a source of renewable energy in Malaysia. Renewable and Sustainable Energy Reviews, $19,454-462$

Jahandideh-Tehrani, M., Bozorg Haddad, O., \& Loáiciga,H. A. (2015). Hydropower Reservoir Management Under Climate Change: The Karoon Reservoir System. Water Resources Management, 29(3), 749-770.

Jiekang, W., Zhuangzhi, G., \& Fan, W. (2014). Short-term multiobjective optimization scheduling for cascaded hydroelectric plants with dynamic generation flow limit based on EMA and DEA. International Journal of Electrical Power \& Energy Systems, 57, 189-197.

Koziel, S., \& Yang, X.-S. (2011). Computational optimization, methods and algorithms, Springer.

Labadie, J. W. (2004). Optimal operation of multireservoirsystems: state-of-the-art review. Journal of water resources planning and management, 130(2), 93111.

Lu, B., Li, K., Zhang, H., Wang, W., \& Gu, H. (2013).Study on the optimal hydropower generation of Zhelin reservoir. Journal of Hydro-environment Research, 7(4), 270-278.

Ma, C., Lian, J., \& Wang, J. (2013). Short-term optimal operation of Three-gorge and Gezhouba cascade hydropower stations in non-flood season with operation rules from data mining. Energy Conversion and Management, 65, 616627.

Mahmoudimehr, J., Sorouri, A., \& Feshalami, B. F. (2016). A novel map for deciding on the type of a hydro power plant. Proceedings of the Institution of Civil Engineers-Energy, 169(4), 161-178.

Mantawy, A. H., Soliman, S. A., \& El-Hawary, M. E. (2003). The long-term hydro-scheduling problem-a new algorithm. Electric Power Systems Research, 64(1), 67-72.

Marano, V., Rizzo, G., \& Tiano, F. A. (2012). Applicationof dynamic programming to the optimal management of a hybrid power plant with wind turbines, photovoltaic panels and compressed air energy storage. Applied Energy, 97, 849-859.

Mariano, S. J. P. S., Catalao, J. P. S., Mendes, V. M. F., \&Ferreira, L. A. F. M. (2007). Profit-Based Short-Term Hydro Scheduling considering Head-Dependent Power Generation. Power Tech, 2007 IEEE Lausanne.

Mariano, S. J. P. S., Catalão, J. P. S., Mendes, V. M. F., \&Ferreira, L. A. F. M. (2008). Optimising power generation efficiency for head-sensitive cascaded reservoirs in a competitive electricity market. International Journal of Electrical Power \& Energy Systems, 30(2), 125-133.

Newables 2005: Global statusreport. Washington, DC: Worldwatch Institute.

Nautiyal, H., Singal, S., \& Sharma, A. (2011). Small hydropower for sustainable energy development in India. Renewable and Sustainable Energy Reviews, 15(4), 2021-2027.

Pérez-Díaz, J. I., \& Wilhelmi, J. R. (2010). Assessment of the economic impact of environmental constraints on short-term hydropower plant operation. Energy Policy, 38(12), 79607970.

Pérez-Díaz, J. I., Wilhelmi, J. R., \& Sánchez-Fernández, J.Á. (2010). Short-term operation scheduling of a hydropower plant in the day-ahead electricity market. Electric Power Systems Research, 80(12), 1535-1542.

Sharma, V., Jha, R., \& Naresh, R. (2007). Optimal multi-reservoir network control by augmented Lagrange programming neural network. Applied Soft Computing, 7(3), 783-790.

Simopoulos, D. N., Kavatza, S. D., \& Vournas, C. D. (2007). An enhanced peak shaving method for short term hydrothermal scheduling. Energy Conversion and Management, 48(11), 3018-3024.

Xu, J., \& Tao, Z. (2012). A class of multi-objective equilibrium chance maximization model with twofold random phenomenon and its application to hydropower station operation. Mathematics and Computers in Simulation, 85, 11-33.

Yang, T., Gao, X., Sellars, S. L., \& Sorooshian, S. (2015).Improving the multi-objective evolutionary optimization algorithm for hydropower reservoir operations in the California OrovilleThermalito complex. Environmental Modelling \& Software, $69,262-279$

Yoo, J.-H. (2009). Maximization of hydropower generation through the application of a linear programming model. Journa of Hydrology, 376(1), 182-187.

Zhang, R., Zhou, J., Ouyang, S., Wang, X., \& Zhang, H. (2013). Optimal operation of multi-reservoir system by multi-elite guide particle swarm optimization. International Journal of Electrical Power \& Energy Systems, 48, 58-68.

Zhao, G., \& Davison, M. (2009). Optimal control of hydroelectric facility incorporating pump storage. Renewable Energy, 34(4), 1064-1077. 